\title{
UAS RTK / PPK photogrammetry as a tool for mapping the urbanized landscape, creating thematic maps, situation plans and DEM
}

\author{
Ludovít KOVANIČC $\check{L}^{1,2 *}$, Peter BLISTAN ${ }^{3,4,5}$, Michal ROZLOŽNÍK ${ }^{6}$ and Gergely SZABÓ
}

Authors' affiliations and addresses:

${ }^{1}$ Institute of Geodesy, Cartography and Geographical Information Systems, Faculty of Mining, Ecology, Process Control and Geotechnology, Technical University Kosice, Park Komenského 19, 04001 Košice, Slovak Republic

e-mail: ludovit.kovanic@tuke.sk

${ }^{2}$ Centrum výcviku Lešt', Lešt', 96263 Pliešovce, Slovak Republic

${ }^{3}$ Institute of Geodesy, Cartography and Geographical Information Systems, Faculty of Mining, Ecology,

Process Control and Geotechnology, Technical

University Kosice, Park Komenského 19, 04001

Košice, Slovak Republic

e-mail: peter.blistan@tuke.sk

${ }^{4}$ Centrum výcviku Lešt', Lešt', 96263 Pliešovce,

Slovak Republic

${ }^{5}$ P.B.M.B. Consulting, s.r.o., Košice, Slovak

Republic

${ }^{6}$ EuroGeo - CADaster, s.r.o., Czambelova 2, 04001 Košice, Slovak Republic

e-mail: eurogeocadaster@eurogeocadaster.sk

${ }^{7}$ EuroGeo - CADaster, s.r.o., Czambelova 2, 04001 Košice, Slovak Republic

e-mail: eurogeocadaster@eurogeocadaster.sk

\section{*Correspondence:}

Ludovít Kovanič, Institute of Geodesy, Cartography and Geographical Information Systems, Faculty of Mining, Ecology, Process Control and

Geotechnology, Technical University Kosice, Park Komenského 19, 04001 Košice, Slovak Republic e-mail: ludovit.kovanic@tuke.sk

Funding information:

KEGA agency - Grant No: KEGA 055TUKE4/2021, APVV agency - Grant No: APVV-18-0351, VEGA agency - Grant No: VEGA 1/0588/21, European Regional Development Fund - ITMS code 313011AUP1,

How to cite this article:

Kovanič, L., Blistan, P., Rozložník, M. and Szabó, G. (2021). UAS RTK / PPK photogrammetry as a tool for mapping the urbanized landscape, creating thematic maps, situation plans and DEM. Acta Montanistica Slovaca. Volume 26 (4) 649-660

DOI:

https://doi.org/10.46544/AMS.v26i4.05

\begin{abstract}
The creation of map works is one of the primary tasks of a surveyor. In contrast to conventional geodetic measurement methods, photogrammetric methods are often used in combination with RPAS (Remotely piloted aircraft systems). The result of aerial photogrammetric measurements is usually an orthophoto map and a digital elevation model (DEM). In this article, we focused on creating topographic map data from RPAS aerial photogrammetry in the builtup area, where such maps are missing. Ground control points (GCP) are standard for georeferencing of photogrammetric measurements. In our approach, we verified the possibility of mapping completely without the surveyors entering the area of interest. The quality of georeferencing the model using RTK / PPK data without GCP was verified. At checkpoints (CP), average mean errors of $0.031 \mathrm{~m}$ in position and $0.112 \mathrm{~m}$ in height were achieved. A DEM, orthophoto map and point cloud were generated from the photogrammetric measurements, and surface maps were created from them. The map data obtained by the two vectorization procedures were compared using identical points. The difference in position reached the mean error value of $0.074 \mathrm{~m}$, resp. $0.042 \mathrm{~m}$ compared to the cadastral map. The result of the whole data processing process are also various other forms of visualization of the obtained data, e.g. coloured point cloud, textured 3D mesh surface, terrain slope analysis, etc.
\end{abstract}

\section{Keywords}

RTK/PPK photogrammetry, SfM, RPAS, UAV, UAS, point-cloud, DEM, thematic map 


\section{Introduction}

The digital terrain model (DTM) is the primary basis for evaluating the nature of georelief in natural and urbanized landscapes. Using software tools, including GIS, it is possible to draw conclusions using spatial analyses applicable in various technical and scientific areas of research (Bindzárová et al., 2020), (Jacko et al., 2021). The basis for DEM formation is a set of measured points defined by coordinates (Salach et al., 2018). The choice of surveying method corresponds to the requirements for the density of the model, its accuracy, the size of the surveyed area, the possibility of movement in it and other technical or specific characteristics (Kociuba, 2020), (Suo et al., 2020). Conventional geodetic, photogrammetric and lidar methods are mainly used to collect spatial data for DEM creation (Wang et al., 2020). The primary geodetic method is the spatial polar method using total stations (TS). It is a selective, most frequent contact method of surveying selected characteristic points with the need to move the surveyor in the locality of interest. Measurements using Global Navigation Satellite Systems (GNSS) can also be used in the open country. A common advantage of these methods can be high surveyed point accuracy and low input costs. Disadvantages are low achievable surveyed point density and low speed of fieldworks. Motorized total stations and terrestrial laser scanners (TLS) have become an increasingly common technology in recent years. We consider such data collection to be non-selective but using conventional measurement procedures. The advantage of TLS, in particular, is the high density of measured data. The disadvantage is the high acquisition costs (Erdélyi et al., 2018). TLS have been tested and are used in various research, especially in construction (Bariczová et al.), (Erdélyi et al. 2020), mining (Štroner et al., 2019), (Kovanič et al., 2020), (Saderova et al., 2020), (Sofranko et al., 2020), engineering and industry (Malowany et al., 2015), (Sofranko et al., 2014), (Wittenberger et al., 2015), in the underground mapping (Gallay et al., 2016), archaeology (Marín-Buzón et al. 2021), etc. The current application of lidar technology can be considered mobile laser scanning using, e.g. SLAM (Simultaneous Localization and Mapping) technology, which provides higher efficiency of measurement work while achieving acceptable measurement accuracy.

Airborne laser scanning (ALS) is an active non-contact measurement method capable of highly detailed mapping of the earth's surface, even in conditions where other measurement methods are limited by its principle or physical characteristics. The obtained data create a relatively homogeneous point field with a point spacing of several $\mathrm{dm}$ to several meters with an accuracy of centimetres or decimetres. The level of accuracy depends on many factors (e.g., flight altitude, pitch angle, scanner parameters, inertial system, and GNSS accuracy) (Pelicani et al., 2019). The advantages of ALS are especially evident in cases where a rapid collection of topographic spatial data at a large scale site with high data density and accuracy is required (Siwiec, 2018), (Kovanič et al., 2021), (Bindzárová et al., 2021). The main advantage of ALS is the ability to reconstruct the terrain under the vegetation cover, which allows deriving more accurate DTM even in densely forested areas (Fernández et al., 2021). However, more frequent deployment of ALS is limited mainly by high input and operating costs. Photogrammetric methods of creating 3D models are probably the most widespread contactless spatial data collection. The reason is mainly the availability of digital cameras, progress in the development of software solutions and, last but not least, the development of remotely controlled aircraft systems (RPAS, UAS). The advantage is also the acquisition of 3D data with complete and homogenous coverage over the entire area. A priori accuracy can also be calculated with respect to the distance from the object, the size of the object, the parameters of the camera, the location and the amount of GCP, etc. Accuracy and quality are assessed by research (Yurtseven, 2019), (Urban et al., 2019).

The application of photogrammetric methods is in various disciplines, e.g. construction (Janowski et al., 2016), (Marčiš et al., 2017), (Bartoš et al., 2019), industry (Ajayi et al., 2021), (Kovanič et al., 2020), mining (Ren et al., 2019), ( Park et al., 2020), archaeology (Marín-Buzón et al. 2021), agriculture (Marín-Buzón et al. 2020), underground (Pukanská et al., 2020), in various environmental conditions (Burdziakowski et al., 2021). The advantages are, in particular, the short time required for measurement, the high density of measured points and the detail of the resulting model, low input and operating costs and high accuracy. From the point of view of camera position, we divide photogrammetry into terrestrial and aerial. Aerial photogrammetry uses piloted or more available unmanned aerial vehicles. The "Structure - from - Motion" (SfM) method is one of the most advanced methods of photogrammetric image processing. The SfM - Multi-View Stereo (MVS) method involves the simultaneous determination of the internal and external orientation of the camera and the 3D structure captured from the images. The main advantage of the SfM - MVS method is the availability of its deployment in practice. It is characterized by low input and operating costs for hardware. Furthermore, photogrammetric procedures can be used to document a dynamic scene (Marčiš et al., 2021), (Kovanič et al., 2021).

Ground Control Points (GCP) are used for georeferencing of photogrammetric data (Ren et al., 2020). Their coordinates are determined by geodetic methods. In the images, their position is marked manually or automatically during processing (Štroner et al., 2021). The second option is to use RTK / PPK camera positioning while imaging, where each image has assigned an exact position (Zeybek, 2021), (Štroner et al., 2021). GCPs are not necessary in this case (Štroner et al. 2020), (Žabota and Kobal 2021); however, the establishment of Check Points (CP) is recommended. By comparing their coordinates from geodetic measurements and determined on the model, we determine the true accuracy of the model and georeferencing. The authors addressed the classification of lidar and 
photogrammetric data in works (Štroner et al., 2021), (Klápště et al., 2020), (Janowski et al., 2018), (Zeybek et al., 2020), (Mielcarek et al., 2020).

\section{Material and Methods}

At present, even in mapped areas covered by DEM and digital maps, we often encounter the need to:

- accurately locate phenomena,

- operationally document current changes in the territory,

- create current orthophotos,

- create an up-to-date thematic map, topographic map,

- identify changes in the locality of interest in the recent period.

For these types of tasks, it is most effective to use methods that offer fast, accurate and efficient data collection. By processing them, we obtain complex outputs - derivatives (DSM, DEM, DEM analysis, orthophoto

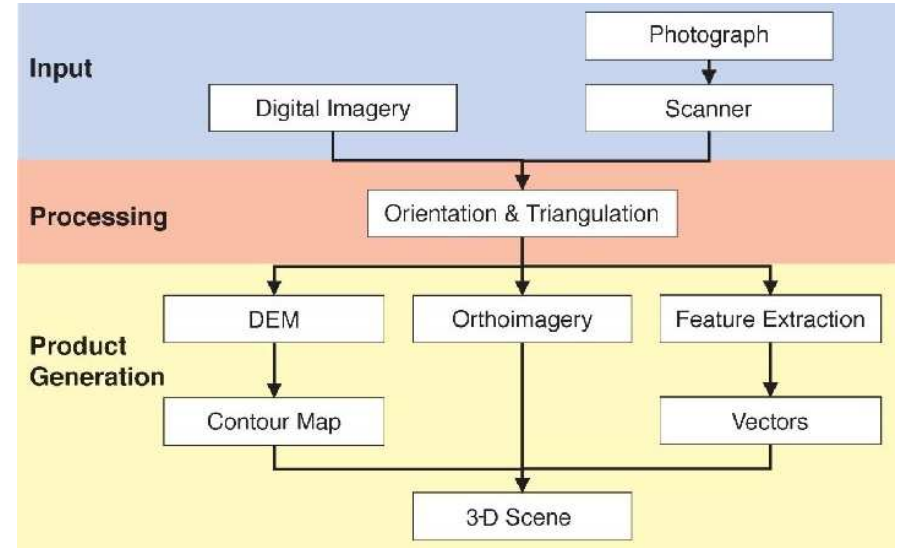

Fig. 1. Typical photogrammetry workflow maps, digital maps, etc.), usable for multiple purposes. Our research aimed to test the accuracy and quality of DSM and purpose maps obtained from photogrammetric data using RTK / PPK RPAS equipment. For these purposes, a location was selected where it is necessary to create an actual map to identify and locate new objects. The locality has undergone significant changes in the landscape in recent years. Although these changes were not documented, the current topographic and cadastral maps were missing. When collecting and processing data, we followed the typical procedures for processing photogrammetric data - Fig. 1.

\section{The Object of Research - Study Area}

A locality on the outskirts of a village in Eastern Slovakia was selected to implement our research (Fig. 2). In the mapped area, there are mainly unauthorized and unregistered buildings in the available map works and documents, which need to be located - for maps creation. The area of interest is approximately $30,000 \mathrm{~m}^{2}$, and the maximum elevation reaches $25 \mathrm{~m}$. There are about 30 unregistered and two registered buildings. They are shown in Figure 3.

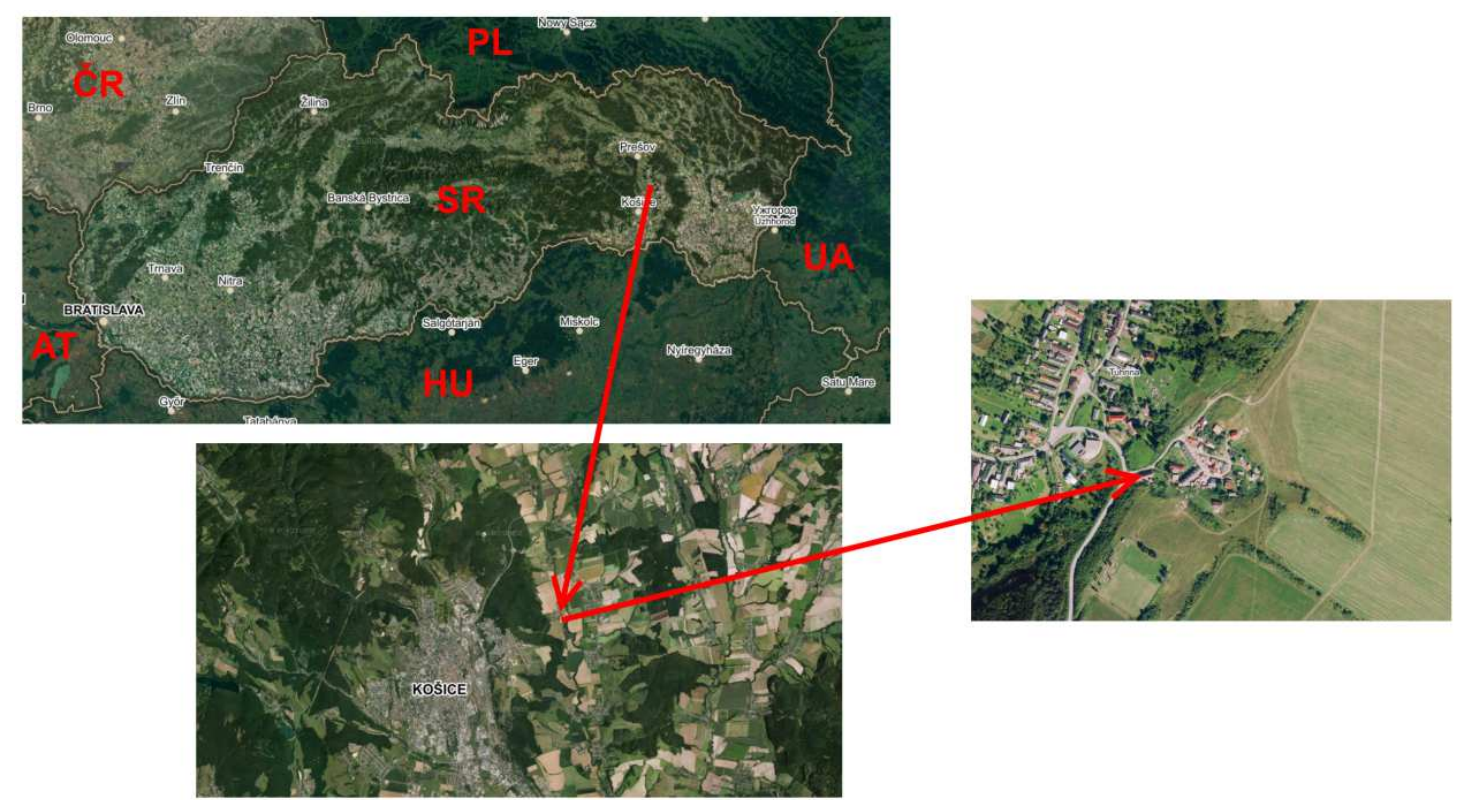

Fig. 2. Area of interest 


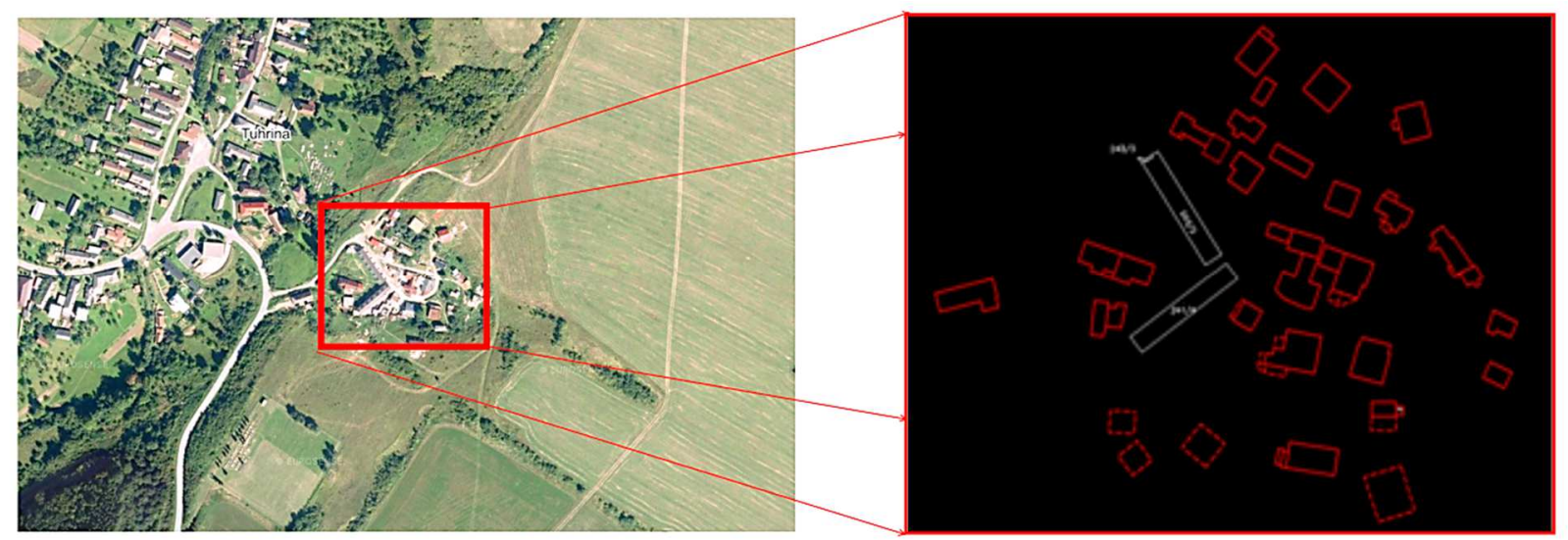

Fig. 3. Position of objects in the area of interest

\section{Surveying Equipment and Data Acquisition}

The image flight was performed by RPAS DJI Phantom 4 RTK (Fig. 4). It is a currently produced, affordable model with an RTK / PPK module with recording in the Exif metadata of each image. The FC6310R camera with a focal length of $8.8 \mathrm{~mm}$ is equipped with a CMOS sensor size 13.2 x $8.8 . \mathrm{mm}$. Other selected technical characteristics of RPAS are listed in Tab. 1.

Table 1. UAS DJI Phantom 4 RTK characteristics.

\begin{tabular}{cccc}
\hline & Aircraft & & Camera \\
\hline Weight (with Battery and & $1391 \mathrm{~g}$ & Operating Environment & Temperature: \\
Propellers): & $6 \mathrm{~m} / \mathrm{s} / 3 \mathrm{~m} / \mathrm{s}$ & Sensor: & $0-40{ }^{\circ} \mathrm{C}$ \\
Max Ascent/Descent Speed: & $50 \mathrm{~km} / \mathrm{h}$ & Effective Pixels: & I" CMOS \\
Max Flight Speed: & $30 \mathrm{~min}$ & Image size: & 4864 pixels $\times 3648$ pixels $(4: 3)$ \\
Max. flight time: & Single-frequency & & \\
& GPS+GLONASS+Galileo & Gimbal pitch & -90 to $+30^{\circ}$ \\
GNSS & Multi-frequency & & \\
& L1/L2+L1/L2+E1/E5a & & \\
Positioning accuracy & Horizontal: $1 \mathrm{~cm}+1 \mathrm{ppm}$ & & \\
\hline
\end{tabular}

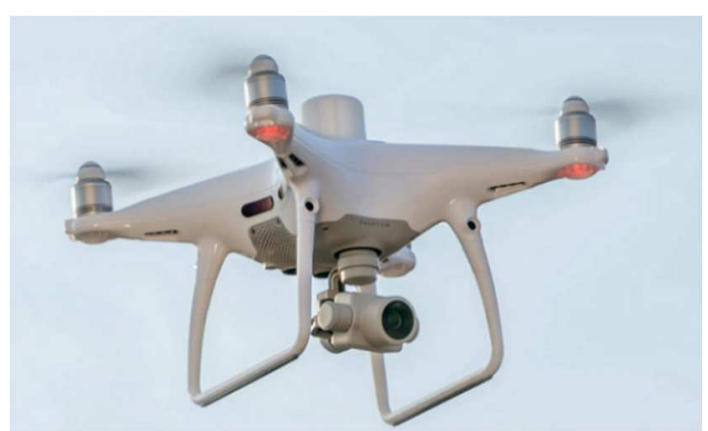

Fig. 4. RPAS Phantom 4 RTK

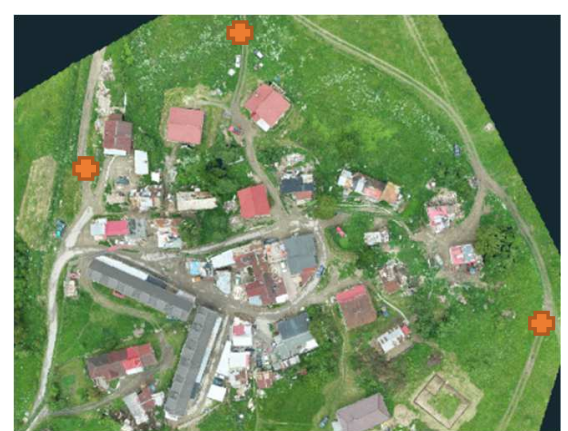

Fig. 5. Localization of $G C P / C P$

In the locality of interest, 3 GCPs/CPs were deployed. They were signalled by plastic circular targets attached to the terrain with central nails. They were stabilized temporarily - just for this research. GNSS measurement with RTK (real-time kinematic) method using a connection to the Slovak Real-time Positioning Service (SKPOS) was used to determine the coordinates of these GCPs/CPs. The Leica antenna GS07 with the CS20 controller was used. The antenna was placed on a standard pole with a rectified circular level. An additional stand supported centering during the measurement. Observation on every point was set for 3 minutes. It corresponds to an average of 900 measurements. The maximum standard deviation of these points was assumed to be $20 \mathrm{~mm}$ in position and $40 \mathrm{~mm}$ in height. The configuration of GCPs/CPs is shown in Figure 5. They were used to connect terrestrial measurements to the standard reference system in the Slovak Republic - Datum of Uniform Trigonometric Cadastral Network (S-JTSK) and Baltic Vertical Datum — after adjustment (Bpv). The implementation of JTSK performed by the transformation key according to the departmental transformation service of the Slovak Republic (ZBGIS) was used. GSD (Ground Sampling Distance) was a priori estimated in preparation for the flight. 
Regarding the planned flight altitude and camera parameters, its maximum value was derived at $25 \mathrm{~mm}$. The flight was performed with a start at the highest point in the locality with a set height of $55 \mathrm{~m}$, which represents the minimum height AGL (above ground level). For flight planning, the GS RTK application was used. A double-grid mission with a camera inclination of $55^{\circ}$ was set. In the second flight with a single-grid configuration, vertical images were obtained. The longitudinal and transverse overlap was $80 \%$ on both imaging flights. RTK corrections were transmitted via the SKPOS service. In total, 347 images were captured.

\section{Results and discussion}

\section{SfM data processing}

Photogrammetric processing was performed by 3D survey software ver. 2.13.1. using the SfM-MVS method. Bundle adjustment was performed with "high" value and bundle orientation based on telemetry data. All 347 images were aligned. The average mean error of bundle adjustment is expressed in tab. 2. Transformation of telemetric coordinates of images was performed using the web interface of the departmental transformation service (RTS) of the Office of Geodesy, Cartography and Cadastre of the Slovak Republic (UGKK SR). Scaling and georeferencing were performed based on these data only. GNSS checkpoints were used to check and validate the accuracy and location of the model. Residual errors at the checkpoints are listed in Tab. 3.

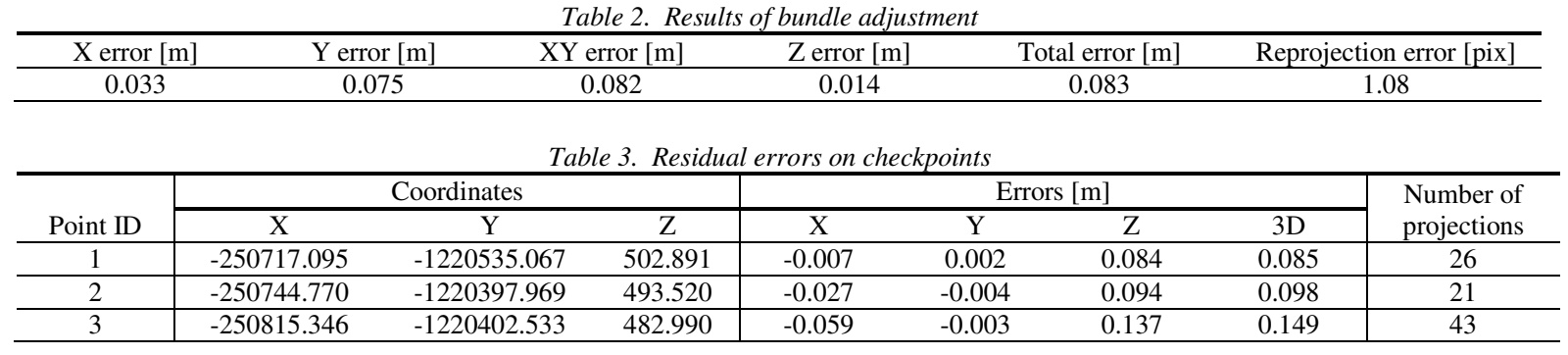

After an orientation of the model, the reconstruction and generation of a dense point cloud with a "high" setting were performed. Altogether, approximately 105 million points were generated. The average GSD value of the whole point-cloud is at the level of $29 \mathrm{~mm}$. After trimming the area of interest, we worked with 36 million points (Fig. 6).

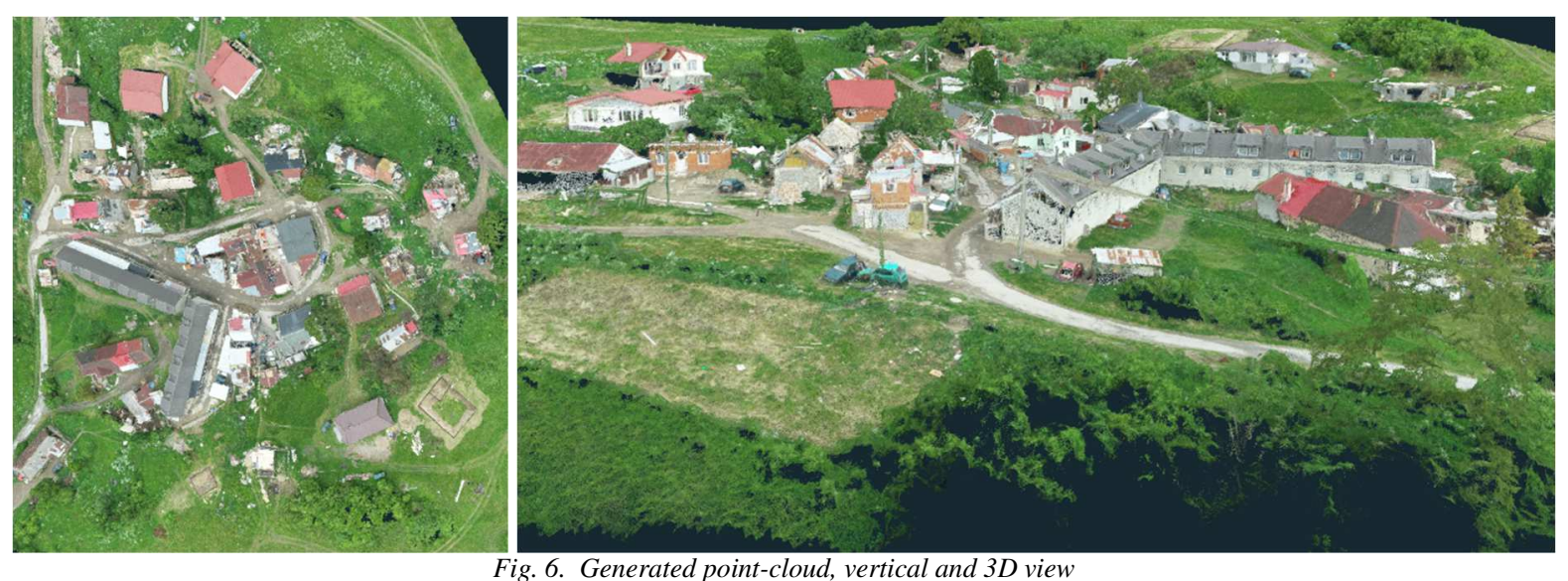

\section{Creation of vector map materials}

One of the main goals of our research was to create thematic 2D maps from the obtained photogrammetric data, which was later used to locate buildings and other objects. We used two approaches to generate map data:

- Vectorization of the raster background in the form of an X-ray georeferenced tif file

- Vectorization of horizontal sections of 3D point cloud 


\section{Vectorization of the raster background in the form of a georeferenced $X$-ray file}

The vectorization of the raster background in the form of a georeferenced X-ray file and the preparation of additional data was performed according to the following procedure: Using the "X-ray" tool of the 3Dsurvey software - a georeferenced raster file was obtained showing points corresponding to points on object edges. Due to the use of oblique images, which also capture the vertical structures of buildings, it was possible to comprehensively reconstruct this part of the buildings in the selected location (Fig. 6. Right). Figure 7 on the left is a general view, Figure 7 on the right is a detail. Vectorization of selected control structures was performed in a 2D drawing file using Bentley Microstation software. Figure 8 shows selected control objects with assigned checkpoints.
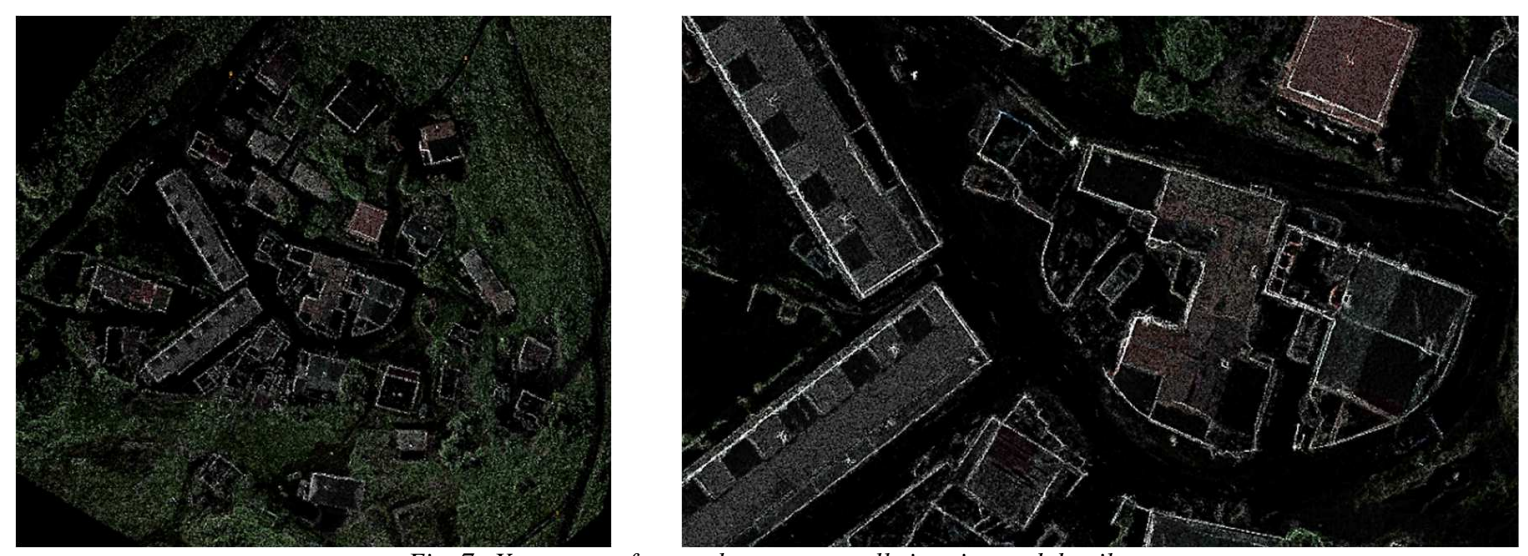

Fig. 7. X-ray georeferenced raster, overall situation and detail
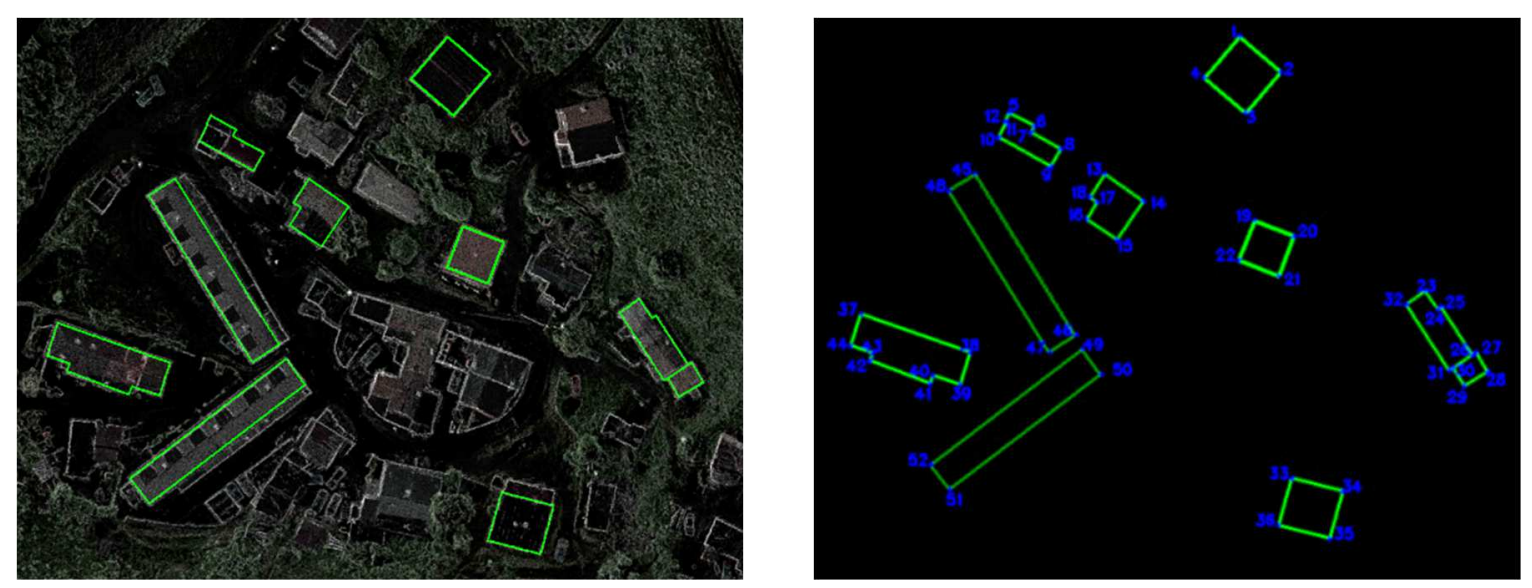

Fig. 8. Vectorization based on georeferenced X-ray raster and generation of checkpoints

\section{Vectorization of horizontal sections of $3 D$ point cloud}

Using Bentley Microstation software, vectorization based on a section of the point-cloud was also performed. The attached 3D point-cloud was manually trimmed by unnecessary elements and objects using the Clip function to create sections of this cloud for individual objects. The sequence of these sections was forced by the different height levels of every object (Fig. 9). 

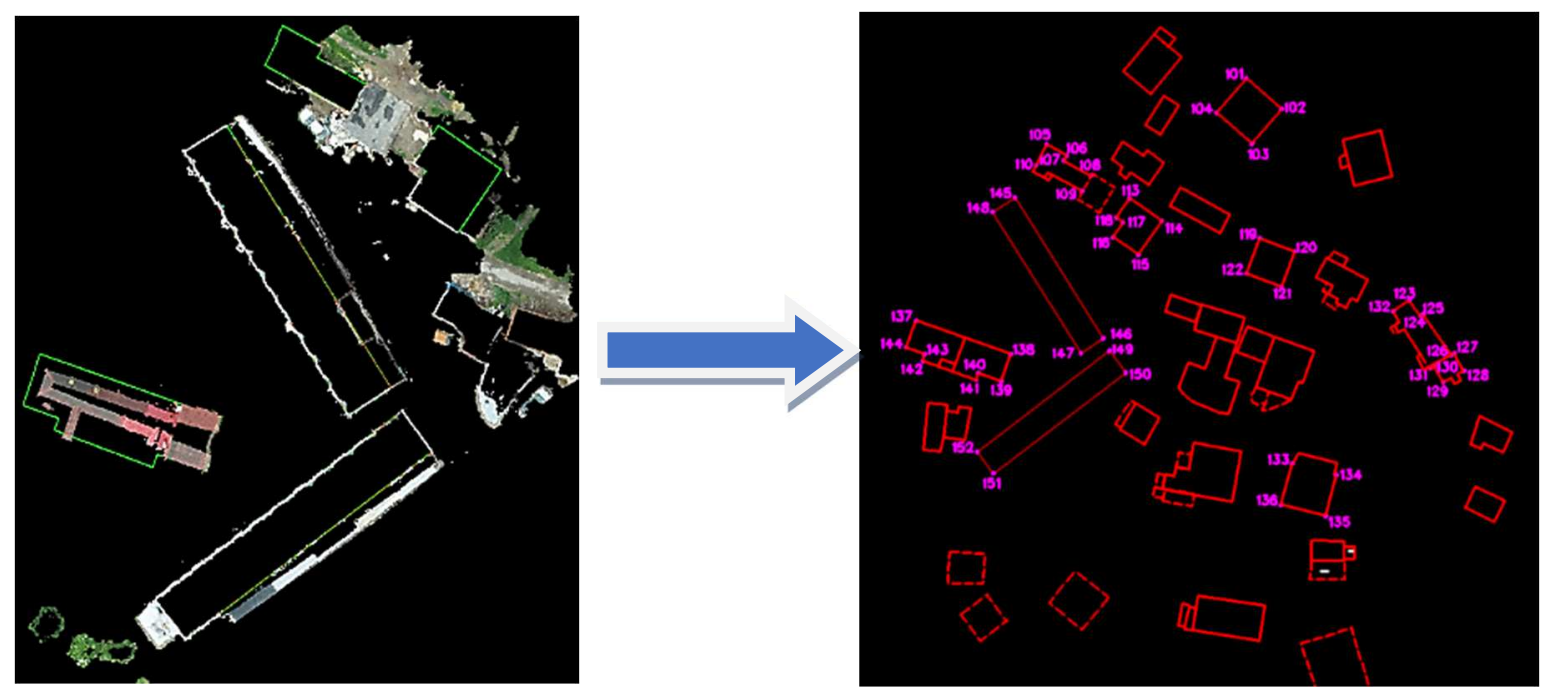

Fig. 9. Vectorization based on horizontal sections of 3D point-cloud and generation of checkpoints

\section{Quality and evaluation of results}

The standard deviation $\sigma$ of the data file is the square root of the variance of the file and is, in general, calculated by the formula

$$
\sigma=\sqrt{\frac{1}{(n-1)} \sum_{i=1}^{n}\left(d_{i}-\bar{d}\right)^{2}}
$$

where: $n$ is the number of observations, $d_{i}$ is the data value, and $\bar{d}$ is the mean.

The values $d_{i}$ represent the lengths of the vectors between the coordinates determined by the two vectorization methods, resp. between the vectorized data and the state according to the cadastral map. Determined by equation (2)

$$
d_{i}=\sqrt{\Delta y^{2}+\Delta x^{2}}
$$

By comparing the mutual results of the two vectorization methods, a standard deviation $\sigma_{\text {vect }}=0,074 \mathrm{~m}$ was determined at 52 control points. Finally, the standard deviation $\sigma_{k a t}=0,042 m$ value was determined by comparing the vectorized points according to the available cadastral map data.

\section{Application of results in practice}

Photographs, surveying images, maps and spatial models have their irreplaceable position in applied research. In addition to the visualization of the studied phenomena, the constructed works can also provide spatial information. A significant source of spatial data are aerial images, survey images or orthophoto maps obtained and processed by remote sensing methods (LANDSAT, Quickbird, GeoEYE, IKONOS and aerial survey data). The main advantage of mapping in small and medium scales is their content or information density and the spatial localization of the phenomena they capture. The disadvantage lies in the relatively high cost of data and the discontinuity of surveying the area for current research needs (satellites orbit at intervals of several days or weeks). The use of such images in large-scale mapping may also be problematic, where they may not provide sufficient information density. In addition, if operational surveillance of a small area several times a year is required (e.g. environmental monitoring), the deployment of scanning aircraft or helicopters may be inefficient. For these reasons, it is advantageous to use unmanned aircraft systems (UAS), which represent a large group of unmanned aerial systems for spatial data collection (Sládek and Rusnák, 2013).

\section{Benefits of RPAS in Surveying:}

- Less Time consumption $\&$ cost-effective - RPAS topographic data collection is five times faster than the traditional land surveying methods. Human resources consumption is less using the PPK geotagging facility, 
which means there is no need to place a lot of GCPs. While choosing this RPAS technology, the end product will be ready faster at a low cost.

- High Precision and Accuracy - Traditional survey methods like total stations measure only one individual point at a time. RPAS collect thousands of points in a short time, and the points are represented in various data formats. Each pixel in the finally created orthophoto or point of the 3D model contains 3D real-world coordinates.

- Low risk \& Climate independent - RPAS surveys can be conducted anywhere, including unsafe steep slopes, dense forests, hilly \& harsh terrains, suitable to different climatic conditions like cloud cover areas, and high busiest areas like metropolitan areas (Agiratech, 2021).

\section{The standard formats of RPAS survey and products are:}

- Orthomosaic Maps - collected RPAS images are preprocessed (corrected, distorted, and mosaiced ) and then create high accurate ortho mosaic photos. Each pixel in the orthomosaic photos contains 2D geographical information (latitude and longitude). It is used to find precise horizontal measurements. Some of the orthomosaic file formats are TIFF, GeoTIFF, Jpg. (Fig. 10).

- 3D Point Cloud - for the area and volumetric measurements, densified 3D point clouds are utilized. The densified point clouds are generated from preprocessed RPAS images. Each point in the cloud carries 3D geographic information (Latitude, Longitude, and Altitude). The file formats to store the 3D point cloud are .las, .laz, .xyz, Ascii. etc. (Fig. 11 and 12).

- $\quad$ 3D Textured Mesh - edges, faces, vertices, and texture of the RPAS data are reproduced and then applied in a 3D textured mesh. It is widely used for visual inspection. Some file formats for storing 3D textured mesh are .pdf, .dxf, .obj, etc.

- Digital Surface Models (DSM) - DSMs are created from the RPAS images. Each pixel holds 3D information (Latitude, Longitude, and altitude). Some file formats are GeoTIFF, .xyz, .las, .jpeg, etc.

- Digital Terrain Model (DTM) - After removing objects in the field, such as building in the RPAS images, DTM can be created. File formats: GeoTIFF. (Fig. 13).

- Contour Lines - contours can be generated from the DTM or DSM model generated from the RPAS images. It gives a clear representation of the surface in the vector data format. Some of the file formats such as .shp, .lyr, .dxf, .tab, .dwg (Agiratech, 2021) (Fig. 14).

- Maps and sections - based on orthomosaic, Digital Terrain Model and 3D Point-Cloud created by manual, semi-automatic or automatic digitalization generated topographic maps, thematic maps, sketches and crosssections in formats .dgn, .dxf, .dwg, .shp, etc. (Fig. 15).

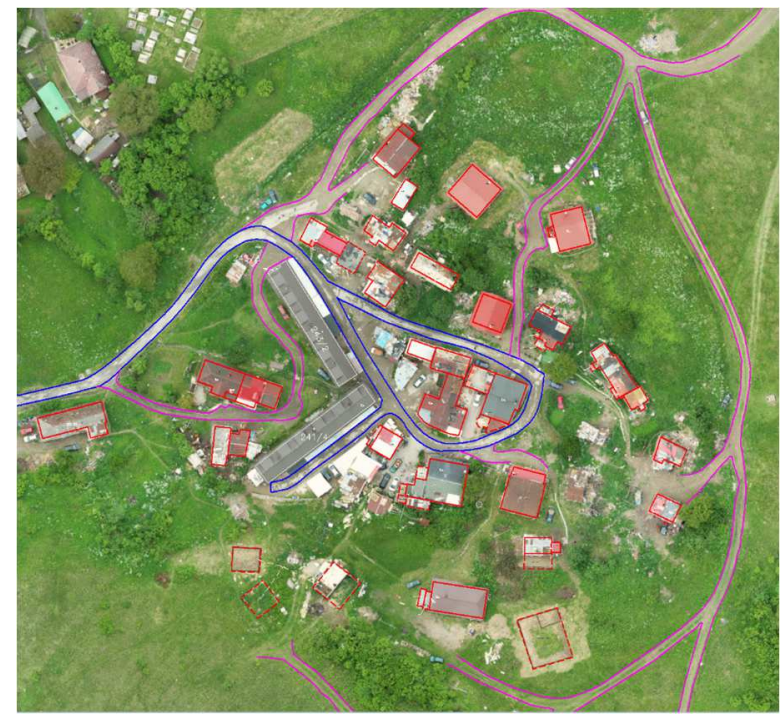

Fig. 10. Orthophoto supplemented by vectorized drawing

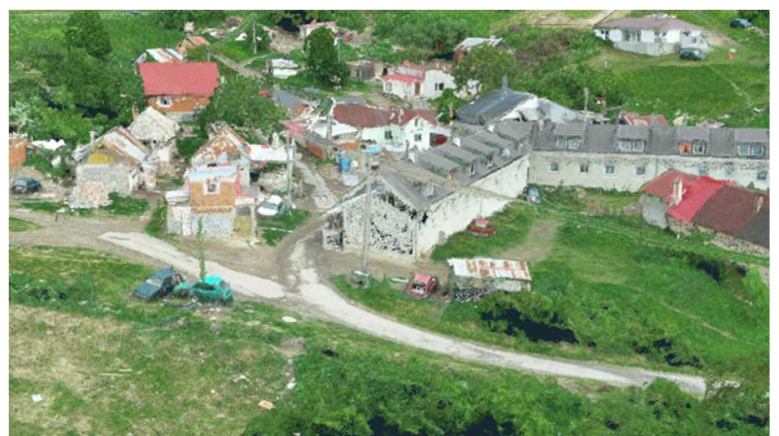

Fig. 11. 3D Point Cloud 


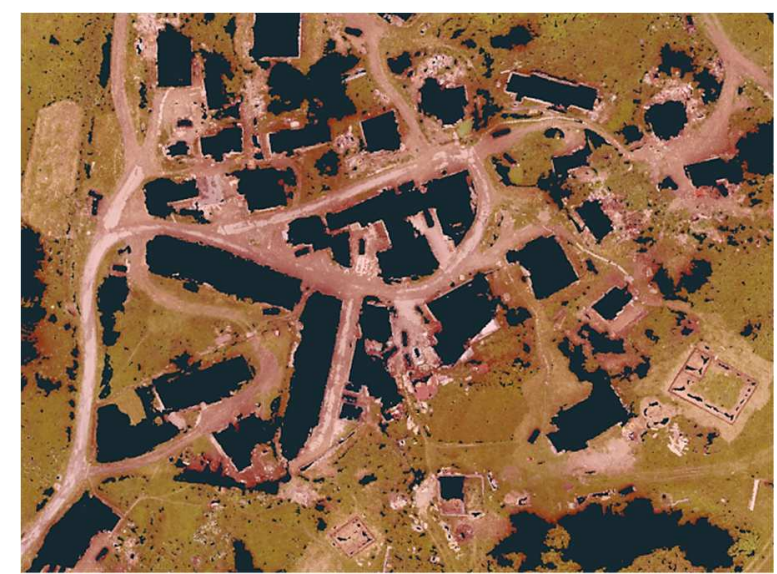

Fig. 12. Classified point-cloud for DTM

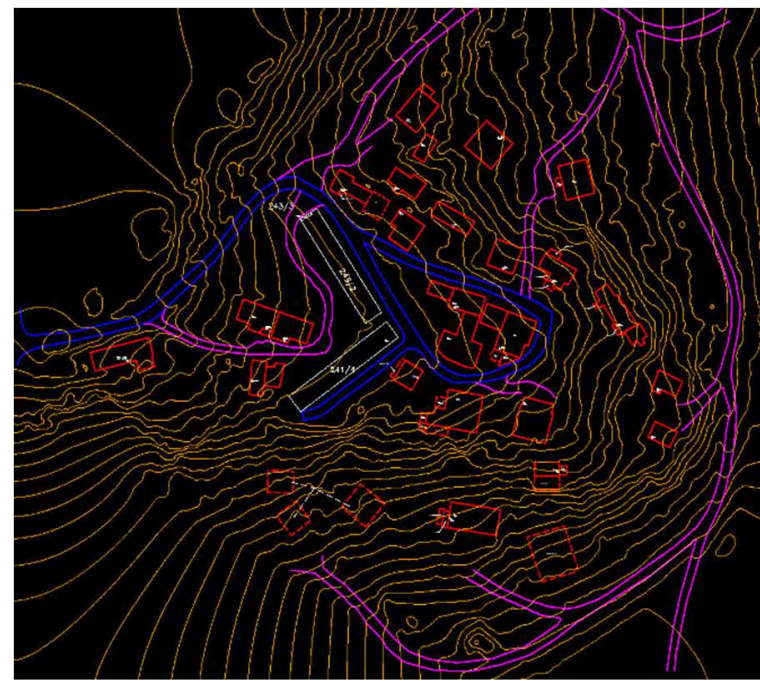

Fig. 14. Vectorized drawing created based on DTM and supplemented by elevation expressed in contour lines.

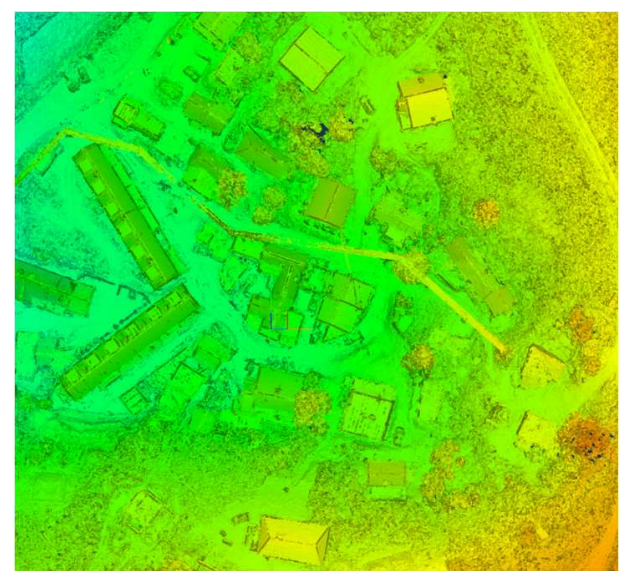

Fig. 13. DTM

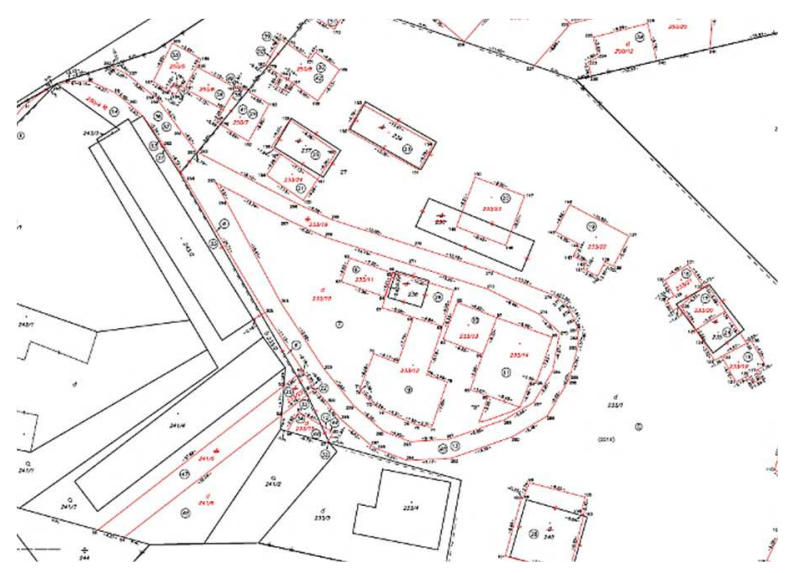

Fig. 15. Thematic map - survey sketch

\section{Conclusions}

This article aimed to practically verify and present the possibilities of using RPAS RTK / PPK photogrammetry for the needs of:

- mapping changes in the urban landscape and the location of objects and phenomena,

- a creation of topographic maps, thematic maps and site plans,

- a creation of digital landscape models and their derivatives.

RPAS RTK / PPK photogrammetry gives better results than "classic" low-cost UAV photogrammetry without the need for GCP. RTK/ PPK approach eliminates the need for the surveyor to enter technically or physically inaccessible areas or on inaccessible areas or dangerous objects. Results of our research indicate that the average mean error of bundle adjustment is $0.083 \mathrm{~m}$. Residual georeferencing errors calculated on the check points are $0.031 \mathrm{~m}$ in horizontal and $0.111 \mathrm{~m}$ in the vertical direction. We have achieved this accuracy without the use of GCP. In addition, to verify the accuracy of photogrammetric data collection using the RPAS RTK / PPK approach, we also tested and confirmed the usability of the point cloud, obtained by processing photogrammetric data to create topographic maps and thematic maps, including cadastral maps and plans. By vectorizing a raster image based on the X-ray georeferenced tif file or by vectorizing sections of a 3D point cloud, it is possible to generate high-quality and accurate topographic and thematic maps. The value of standard deviation $\sigma_{\text {vect }}=0,074 \mathrm{~m}$ was determined at 52 control points. The accuracy of the control points achieved by us in the created map with the officially available data in the cadastral map shows a standard deviation $\sigma_{k a t}=0,042 m$, which is at the level of accuracy of GNSS measurements. From the presented research results, we can clearly state that the RPAS RTK / 
PPK technology in conjunction with photogrammetry gives quality and accurate outputs even without using GCP, usable as an equivalent of conventional field geodetic data collection.

\section{References}

Agiratech, Drone-Survey-Mapping-Data-Products. On Line (2021): https://www.agiratech.com/drone-surveymapping-data-products?ref=morioh.com\&utm_source=morioh.com

Ajayi, O.; Ajulo, J. Investigating the Applicability of Unmanned Aerial Vehicles (UAV) Photogrammetry for the Estimation of the Volume of Stockpiles. Quaest. Geogr. 2021, 40, 25-38, doi:10.2478/quageo-2021-0002.

Bariczová, G.; Erdélyi, J.; Honti, R.; Tomek, L. Wall Structure Geometry Verification Using TLS Data and BIM Model. Appl. Sci. 2021, 11, 11804. https://doi.org/10.3390/app112411804

Bartoš, K.; Pukanská, K.; Repáň, P.; Kseňak, L.; Sabová, J. Modelling the Surface of Racing Vessel's Hull by Laser Scanning and Digital Photogrammetry. Remote Sens. 2019, 11, 1526, doi: 10.3390/rs11131526.

Bindzarova Gergelova, M..; Labant, S.; Kuzevic, S.; Kuzevicova, Z.; Pavolova, H. Identification of Roof Surfaces from LiDAR Cloud Points by GIS Tools: A Case Study of Lučenec, Slovakia. Sustainability 2020, 12, 6847. https://doi.org/10.3390/su12176847

Bindzarova Gergelova, M.; Labant, S.; Mizak, J.; Sustek, P.; Leicher, L. Inventory of Locations of Old Mining Works Using LiDAR Data: A Case Study in Slovakia. Sustainability 2021, 13, 6981. https://doi.org/10.3390/su13126981

Burdziakowski, P.; Bobkowska, K. UAV Photogrammetry under Poor Lighting Conditions-Accuracy Considerations. Sensors 2021, 21, 3531, doi:10.3390/s21103531.

Erdélyi, J.; Kopáčik, A.; Kyrinovič, P. Construction control and documentation of facade elements using terrestrial laser scanning. Appl. Geomat. 2018, 10, 113-121, doi:10.1007/s12518-018-0208-4.

Erdélyi, J.; Kopáčik, A.; Kyrinovič, P. Spatial Data Analysis for Deformation Monitoring of Bridge Structures. Appl. Sci. 2020, 10, 8731, doi:10.3390/app10238731.

Fernández, T.; Pérez-García, J.L.; Gómez-López, J.M.; Cardenal, J.; Moya, F.; Delgado, J. Multitemporal Landslide Inventory and Activity Analysis by Means of Aerial Photogrammetry and LiDAR Techniques in an Area of Southern Spain. Remote Sens. 2021, 13, 2110, doi:10.3390/rs13112110.

Gallay, M.; Hochmuth, Z.; Kaňuk, J.; Hofierka, J. Geomorphometric analysis of cave ceiling channels mapped with 3-D terrestrial laser scanning. Hydrol. Earth Syst. Sci. 2016, 20, 1827-1849, doi:10.5194/hess-20$1827-2016$

Jacko, S.; Farkašovský, R.; Ďuriška, I.; Ščerbáková, B.; Bátorová, K. Critical Tectonic Limits for Geothermal Aquifer Use: Case Study from the East Slovakian Basin Rim. Resources 2021, 10, 31. https://doi.org/10.3390/resources10040031

Janowski, A.; Nagrodzka-Godycka, K.; Szulwic, J.; Ziolkowski, P. Remote sensing and photogrammetry techniques in diagnostics of concrete structures. Comput. Concr. 2016, 18, 405-420, doi:10.12989/CAC.2016.18.3.405.

Janowski, A.; Bobkowska, K.; Szulwic, J. 3D modelling of cylindrical-shaped objects from lidar data-An assessment based on theoretical modellingand experimental data. Metrol. Meas. Syst. 2018, 25, 1 , doi:10.24425/118156.

Klápště, P.; Fogl, M.; Barták, V.; Gdulová, K.; Urban, R.; Moudrý, V. Sensitivity analysis of parameters and contrasting performance of ground filtering algorithms with UAV photogrammetry-based and LiDAR point clouds. Int. J. Digital Earth 2020, 13, 1672-1694.

Kociuba, W. Different Paths for Developing Terrestrial LiDAR Data for Comparative Analyses of Topographic Surface Changes. Appl. Sci. 2020, 10, 7409.

Kovanič, L.; Possibilities of terrestrial laser scanning method in monitoring of shape deformation in mining plants. Inżynieria Miner. J. Pol. Miner. Eng. Soc. 2013, 31, 29-41.

Kovanič, L.; Ambriško, L.; Marasová, D.; Blišt’an, P.; Kasanický, T.; Cehlár, M. Long-Exposure RGB Photography with a Fixed Stand for the Measurement of a Trajectory of a Dynamic Impact Device in Real Scale. Sensors 2021, 21, 6818. https://doi.org/10.3390/s21206818

Kovanič, L.; Blistan, P.; Urban, R.; Štroner, M.; Pukanská, K.; Bartoš, K.; Palková, J. Analytical Determination of Geometric Parameters of the Rotary Kiln by Novel Approach of TLS Point Cloud Segmentation. Appl. Sci. 2020, 10, 7652. https://doi.org/10.3390/app10217652.

Kovanič, L'.; Blistan, P.; Urban, R.; Štroner, M.; Blištanová, M.; Bartoš, K.; Pukanská, K. Analysis of the Suitability of High-Resolution DEM Obtained Using ALS and UAS (SfM) for the Identification of Changes and Monitoring the Development of Selected Geohazards in the Alpine Environment-A Case Study in High Tatras, Slovakia. Remote Sens. 2020, 12, 3901. https://doi.org/10.3390/rs12233901. 
Malowany, K.; Magda, K.; Rutkiewicz, J.; Malesa, M.; Kantor, J.; Michoński, J.; Kujawińska, M. Measurements of geometry of a boiler drum by time-of-flight laser scanning. Measurement 2015, 72, 88-95, doi:10.1016/j.measurement.2015.03.040.

Marcis, M.; Frastia, M.; Augustin, T. Measurement of flat slab deformations by the multi-image photogrammetry method. Slovak J. Civ. Eng. 2017, 25, 19-25. https://doi.org/10.1515/sjce-2017-0019.

Marčiš, M.; Fraštia, M.; Hideghéty, A.; Paulík, P. Videogrammetric Verification of Accuracy of Wearable Sensors Used in Kiteboarding. Sensors 2021, 21, 8353. https://doi.org/10.3390/s21248353

Marín-Buzón, C.; Pérez-Romero, A.M.; León-Bonillo, M.J.; Martínez-Álvarez, R.; Mejías-García, J.C.; ManzanoAgugliaro, F. Photogrammetry (SfM) vs. Terrestrial Laser Scanning (TLS) for Archaeological Excavations: Mosaic of Cantillana (Spain) as a Case Study. Appl. Sci. 2021, 11, 11994. https://doi.org/10.3390/app112411994

Marín-Buzón, C.; Pérez-Romero, A.; López-Castro, J.L.; Ben Jerbania, I.; Manzano-Agugliaro, F. Photogrammetry as a New Scientific Tool in Archaeology: Worldwide Research Trends. Sustainability 2021, 13, 5319. https://doi.org/10.3390/su13095319

Marín-Buzón, C.; Pérez-Romero, A.; Tucci-Álvarez, F.; Manzano-Agugliaro, F. Assessing the Orange Tree Crown Volumes Using Google Maps as a Low-Cost Photogrammetric Alternative. Agronomy 2020, $10,893$. https://doi.org/10.3390/agronomy10060893

Mielcarek, M.; Kamińska, A.; Stereńczak, K. Digital Aerial Photogrammetry (DAP) and Airborne Laser Scanning (ALS) as Sources of Information about Tree Height: Comparisons of the Accuracy of Remote Sensing Methods for Tree Height Estimation. Remote Sens. 2020, 12, 1808, doi:10.3390/rs12111808.

Park, S.; Choi, Y. Applications of Unmanned Aerial Vehicles in Mining from Exploration to Reclamation: A Review. Minerals 2020, 10, 663. doi:10.3390/min10080663.

Pellicani, R.; Argentiero, I.; Manzari, P.; Spilotro, G.; Marzo, C.; Ermini, R.; Apollonio, C. UAS and Airborne LiDAR Data for Interpreting Kinematic Evolution of Landslide Movements: The Case Study of the Montescaglioso Landslide (Southern Italy). Geosciences 2019, 9, 248.

Pukanská, K.; Bartoš, K.; Bella, P.; Gašinec, J.; Blistan, P.; Kovanič, L. Surveying and High-Resolution Topography of the Ochtiná Aragonite Cave Based on TLS and Digital Photogrammetry. Appl. Sci. 2020, 10, 4633. https://doi.org/10.3390/app10134633.

Ren, H.; Zhao, Y.; Xiao, W.; Wang, X.; Sui, T. An Improved Ground Control Point Configuration for Digital Surface Model Construction in a Coal Waste Dump Using an Unmanned Aerial Vehicle System. Remote Sens. 2020, 12, 1623, doi:10.3390/rs12101623.

Ren, H., Zhao, Y., Xiao, W. and Hu, Z. (2019) A review of UAV monitoring in mining areas: current status and future perspectives, International Journal of Coal Science \& Technology, 6(3), pp. 320-333. doi: 10.1007/s40789-019-00264-5.

Saderova, J.; Rosova, A.; Kacmary, P.; Sofranko, M.; Bindzar, P.; Malkus, T. Modelling as a Tool for the Planning of the Transport System Performance in the Conditions of a Raw Material Mining. Sustainability 2020, 12, 8051. doi: 10.3390/su12198051.

Salach, A.; Bakuła, K.; Pilarska, M.; Ostrowski, W.; Górski, K.; Kurczyński, Z. Accuracy Assessment of Point Clouds from LiDAR and Dense Image Matching Acquired Using the UAS Platform for DTM Creation. ISPRS Int. J. Geo-Inf. 2018, 7, 342.

Sládek, J. and Rusnák, M., Nízkonákladové mikro-UAV technológie v geografii (nová metóda zberu priestorových dát). Geografický časopis / Geographical Journal 65 (2013) 3, 269-285

Siwiec, J. Comparison of Airborne Laser Scanning of Low and High Above Ground Level for Selected Infrastructure Objects. J. Appl. Eng. Sci. 2018, 8, 89-96.

Sofranko, M.; Zeman, R. Simulation of pipeline transport backfill mixtures. 15th International Carpathian Control Conference (ICCC), (2014). (578-583). Velke Karlovice, Czech Republic, May 28th -30th 2014, IEEE, 578-583.

Sofranko, M.; Khouri, S.; Vegsoova, O.; Kacmary, P.; Mudarri, T.; Koncek, M.; Tyulenev, M.; Simkova, Z. Possibilities of Uranium Deposit Kuriskova Mining and Its Influence on the Energy Potential of Slovakia from Own Resources. Energies 2020, 13, 4209. doi: 10.3390/en13164209.

Suo, C.; McGovern, E.; Gilmer, A.; Cahalane, C. A comparison of high-end methods for topographic modelling of a coastal dune complex. J Coast Conserv. 2020, 24, 47, doi:10.1007/s11852-020-00764-6.

Štroner, M.; Kremen, T.; Braun, J.; Urban, R.; Blistan, P.; Kovanic, L. Comparison of 2.5D volume calculation methods and software solutions using point clouds scanned before and after mining. Acta Montan. Slovaca 2019, 24, 296-306.

Štroner, M., Urban, R., Reindl, T., Seidl, J. and Brouček, J. (2020) Evaluation of the Georeferencing Accuracy of a Photogrammetric Model Using a Quadrocopter with Onboard GNSS RTK, Sensors, 20(8), p. 2318. doi: $10.3390 / \mathrm{s} 20082318$.

Štroner, M.; Urban, R.; Seidl, J.; Reindl, T.; Brouček, J. Photogrammetry Using UAV-Mounted GNSS RTK: Georeferencing Strategies without GCPs. Remote Sens. 2021, 13, 1336, doi:10.3390/rs13071336. 
Štroner, M., Urban, R. and Línková, L. (2021) A New Method for UAV Lidar Precision Testing Used for the Evaluation of an Affordable DJI ZENMUSE L1 Scanner, Remote Sensing, 13(23), p. 4811. doi: $10.3390 / \mathrm{rs} 13234811$.

Štroner, M., Urban, R., Lidmila, M., Kolář, V. and Křemen, T. (2021) Vegetation Filtering of a Steep Rugged Terrain: The Performance of Standard Algorithms and a Newly Proposed Workflow on an Example of a Railway Ledge, Remote Sensing, 13(15), p. 3050. doi: 10.3390/rs13153050.

Urban, R., Štroner, M., Blistan, P., Kovanič, L., Patera, M., Jacko, S., Ďuriška, I., Kelemen, M. and Szabo, S. (2019) The Suitability of UAS for Mass Movement Monitoring Caused by Torrential Rainfall—A Study on the Talus Cones in the Alpine Terrain in High Tatras, Slovakia, ISPRS International Journal of GeoInformation, 8(8), p. 317. doi: 10.3390/ijgi8080317.

Wang, J.; Wang, L.; Jia, M.; He, Z.; Bi, L. Construction and optimization method of the open-pit mine DEM based on the oblique photogrammetry generated DSM. Measurement 2020, 152, 107322, ISSN 0263-2241.

Wittenberger, G.; Sofranko, M. Formation and protection against incrustation on the geothermal pipe by utilizing of geothermal water in the area of Durkov (Eastern Slovakia). Acta Montan. Slovaca 2015. 10.3390/ams20010010.

Yurtseven, H. Comparison of GNSS-, TLS- and Different Altitude UAV-Generated Datasets on the Basis of Spatial Differences. ISPRS Int. J. Geo-Inf. 2019, 8, 175, doi:10.3390/ijgi8040175.

Zeybek, M.; Şanlığlu, I. Point cloud filtering on UAV based point cloud. Measurement 2019, 133, 99-111. ISSN 0263-2241.

Zeybek, M. Accuracy assessment of direct georeferencing UAV images with onboard global navigation satellite system and comparison of CORS/RTK surveying methods. Meas. Sci. Technol. 2021, 32, 065402.

Žabota, B. and Kobal, M. (2021) Accuracy Assessment of UAV-Photogrammetric-Derived Products Using PPK and GCPs in Challenging Terrains: In Search of Optimized Rockfall Mapping, Remote Sensing, 13(19), p. 3812. doi: 10.3390/rs13193812. 